\title{
Molecular characterization of the desmoplastic tumor stroma in medullary thyroid carcinoma
}

\author{
OSKAR KOPEREK ${ }^{1}$, CHRISTIAN SCHEUBA $^{2}$, CHRISTINA PURI $^{1}$, PETER BIRNER ${ }^{1}$, CHRISTIAN HASLINGER $^{3}$, \\ WOLFGANG RETTIG $^{3}$, BRUNO NIEDERLE ${ }^{2}$, KLAUS KASERER ${ }^{1}$ and PILAR GARIN CHESA ${ }^{1,3}$ \\ ${ }^{1}$ Department of Clinical Pathology, ${ }^{2}$ Section of Endocrine Surgery, Division of General Surgery, \\ Department of Surgery, Medical University of Vienna, Währinger Gürtel 18-20, A-1090 Vienna; \\ ${ }^{3}$ Boehringer Ingelheim Austria GmbH, Dr. Boehringer-Gasse 5-11, A-1120 Vienna, Austria
}

Received February 20, 2007; Accepted April 13, 2007

\begin{abstract}
Medullary thyroid carcinomas are aggressive neoplasias that metastasize very early to loco-regional lymph nodes, and tumors with a desmoplastic stromal reaction have a higher incidence of lymph node metastasis. In order to characterize the desmoplastic response in thyroid cancers, we evaluated the expression pattern of three molecular markers of activated fibroblasts/myofibroblasts, namely, fibroblast activation protein $\alpha(\mathrm{FAP} \alpha)$, tenascin-C (Tn-C), and $\alpha$-smooth muscle actin ( $\alpha$-SMA), as well as the endothelial markers endoglyx-1, CD34 and CD31 in a series of 28 metastatic and non-metastatic medullary thyroid cancers. Immunohistochemical studies demonstrated that the three fibroblast activation markers (FAP $\alpha, \mathrm{Tn}-\mathrm{C}, \alpha-\mathrm{SMA})$ are consistently expressed in the peritumoral and intratumoral stromal compartment of medullary thyroid carcinomas and expression of FAP $\alpha$ and Tn-C correlated with the degree of desmoplasia determined histologically ( $\mathrm{p}=0.001$ for FAP $\alpha$ and $\mathrm{p}<0.001$ for Tn-C). Moreover, the extent of desmoplasia as well as the expression of FAP $\alpha$ and $\mathrm{Tn}-\mathrm{C}$ correlated with the presence of lymph node (LN) metastases $(\mathrm{p}=0.002, \mathrm{p}=0.005$ and $\mathrm{p}=0.002$, respectively). No correlation was found between the microvessel density (neoangiogenesis) in the tumor stroma, assessed with the endoglyx-1, CD34 and CD31 markers, and the degree of desmoplasia or incidence of LN metastases. Using a bioinformatics-based search of the BioExpress ${ }^{\mathrm{TM}}$ database we found in a series of 48 thyroid cancers a significant correlation between FAP $\alpha$ RNA expression and incidence of LN metastases also in papillary cancers. These findings suggest that the link between specific molecular markers of tumor stromal reaction and locoregional metastasis extends from medullary to other thyroid cancer types.
\end{abstract}

Correspondence to: Dr Klaus Kaserer, Department of Clinical Pathology, Medical University of Vienna, Währinger Gürtel 18-20, A1090 Vienna, Austria

E-mail:klaus.kaserer@meduniwien.ac.at

Key words: medullary thyroid carcinoma, desmoplasia, tenascin, fibroblast activation protein $\alpha, \alpha$-smooth muscle actin

\section{Introduction}

Medullary thyroid carcinoma (MTC) accounts for 3-10\% of all thyroid cancers (1). It is derived from the thyroid parafollicular calcitonin-secreting cells (C-cells) and preferentially invades the intrathyroidal lymphatics and the regional lymph nodes (2-4). One distinctive feature of this tumor is the formation of a desmoplastic stroma reaction, which may be accompanied by amyloid deposition. Recent data by our group indicate that the incidence of lymph node metastasis is higher in MTC with a desmoplastic stroma irrespective of the tumor size $(5,6)$.

In many carcinomas, the activation of the host stroma appears to be an indicator of tumor invasion (7-10). The reactive stroma, composed of activated fibroblasts also known as myofibroblasts or cancer associated fibroblasts (CAFs), tumor vessels, inflammatory cells and extracellular matrix components exhibits features analogous to the wound healing process (7). The complex interplay between these different components leads to a remodeling of the extracellular matrix which may promote angiogenesis, tumor cell growth, tumor invasion and metastasis (8-10). The extent of the stroma reaction is, however, highly variable among different tumor types and within individual tumors $(11,12)$.

Recent studies have focused on activated fibroblasts, or CAFs, as the stromal cell types of particular relevance for cancer development and progression (13-15). These activated stromal cells are the source of a variety of regulatory mediators and express markers such as fibroblast activation protein $\alpha$ $(\mathrm{FAP} \alpha)(16,17)$, tenascin-C $(\mathrm{Tn}-\mathrm{C})(18,19)$ and $\alpha$ smooth muscle actin ( $\alpha$-SMA) $(20,21)$.

FAP $\alpha$ is a type II serine protease capable of degrading gelatin and type I collagen. FAP $\alpha$ is selectively expressed by the reactive stromal fibroblasts of several types of human epithelial cancers and in the granulation tissue of healing wounds. Epithelial tumor cells as well as stromal fibroblasts of benign epithelial tumors and most normal adult human tissues lack FAP $\alpha$ expression $(16,17,22-26)$.

$\mathrm{Tn}-\mathrm{C}$ is an extracellular matrix glycoprotein that contributes to pattern formation during development, promotes cell migration, inhibits cell adhesion to fibronectin, and induces tumor proliferation and metastasis in model systems $(18,27-30)$. 
Table I. Primary antibodies.

\begin{tabular}{llllccl}
\hline Antigen & \multicolumn{1}{c}{ Clone } & Host & Dilution & Pretreatment & Tissue type & Source/ref. \\
\hline Tn-C & NEC1b & Mouse & $1: 20$ & No & Frozen & Rettig et al (35) \\
& TN2 & Mouse & $1: 200$ & Protease X & Paraffin & Dako, Glostrup, Denmark \\
FAP $\alpha$ & F19 & Mouse & $1: 20$ & No & Frozen & Garin-Chesa et al (16) \\
$\alpha-S M A$ & 1A4 & Mouse & $1: 200$ & Citrate buffer & Paraffin & Dako \\
CD34 & Qbend/10 & Mouse & $1: 50$ & Citrate buffer & Paraffin & Novocastra, Newcastle, UK \\
CD31 & JC/70A & Mouse & $1: 20$ & No & Paraffin & Dako \\
Endoglyx-1 & H572 & Mouse & $1: 20$ & No & Frozen & Sanz-Moncasi et al (41) \\
Chromogranin A A & DAK-A3 & Mouse & $1: 100$ & No & Frozen & Dako \\
Calcitonin & Polyclonal & Rabbit & $1: 600$ & No & Paraffin & Chemicon, Temecula, CA, USA \\
& Monoclonal & Rabbit & $1: 200$ & No & Frozen & Neomarkers, Fremont, CA, USA \\
\hline
\end{tabular}

Citrate buffer: heat retrieval, $25 \mathrm{~min}$ in $0.1 \mathrm{M}$ citrate buffer $\mathrm{pH}$ 6.0. Protease $\mathrm{X}$ : 10 min protease $\mathrm{X}$.

In carcinomas, $\mathrm{Tn}-\mathrm{C}$ is commonly expressed in the tumor stroma and in certain cancer types in the tumor cells themselves and its expression may correlate with the aggressiveness of the tumors (31-35).

In addition to CAFs, endothelial cells represent another element of the reactive tumor stroma. The process of neoangiogenesis and its role in the growth of solid tumors is well established $(36,37)$ and several studies have shown a correlation between hot spots of microvessel density (MVD) and the invasiveness of solid tumors $(38,39)$.

The present study was designed to analyze the desmoplastic tumor stroma in 28 cases of medullary thyroid cancer (MTC). The expression patterns of FAP $\alpha$, Tn-C and $\alpha$-SMA in the activated tumor stromal fibroblasts were correlated with the presence of lymph node metastasis. In addition, the extent of neoangiogenesis was studied with monoclonal antibodies to endoglyx-1 (41), PECAM (CD31) and CD34, and the results were correlated with the presence of desmoplasia and lymph node involvement. Moreover, the study of medullary thyroid cancers for FAP $\alpha$, Tn-C and $\alpha$-SMA expression was compared with bioinformatics methods to the corresponding mRNA expression patterns in other thyroid cancer types.

\section{Materials and methods}

Study population. The study group consisted of 28 cases of pathological confirmed medullary thyroid carcinomas (MTC). The cancer samples were collected at the Department of Pathology, Medical University of Vienna, in accordance with the guidelines of the institutional ethics committee. The samples were embedded in O.C.T. compound (Tissue Tec ${ }^{\circledR}$, Sakura Finetek , Zoeterwoude, The Netherlands), frozen in liquid nitrogen and stored at $-70^{\circ} \mathrm{C}$ until further use. Formalinfixed, paraffin-embedded tissue samples were available from all cases. Serial $4-\mu \mathrm{m}$ frozen sections and $3-\mu \mathrm{m}$ sections from paraffin-embedded material were cut and used for immunohistochemical analysis, one adjacent section was stained with hematoxylin and eosin (H\&E) and used for histopathological evaluation.
Immunohistochemistry. The avidin-biotin immunoperoxidase complex (ABC) was carried out as described previously (31). The source of the primary antibodies, working concentration and methods of detection are described in Table I. Briefly, slides were incubated overnight at $4{ }^{\circ} \mathrm{C}$ with the primary antibodies followed by incubation with biotinylated secondary antibodies and the avidin-biotin peroxidase complex (ABC) using the Vectastin ABC kit (Vector Laboratories, Burlingame, $\mathrm{CA})$.The final reaction was visualized with 3,3' diaminobenzidine. Negative controls included substitution of primary antibodies by nonspecific, isotype-matched antibodies. Sections were counterstained with Harris' hematoxylin. The expression of the stromal markers Tn-C, FAP $\alpha$ and $\alpha$-SMA was evaluated in all samples in two different tissue compartments, namely, the intratumoral compartment and the peritumoral/perinodular stroma compartment. Immunoreactivity was graded as follows: negative $(-)$; weak $(+)$; moderate $(++)$ and strong $(+++)$. The microvessel density (MVD) was quantified as described $(40,41)$.

Histological evaluation. The presence of desmoplasia was determined on H\&E-stained sections by two pathologists $(\mathrm{OK}, \mathrm{KK})$ with expertise in thyroid pathology in a blinded manner. A desmoplastic stroma reaction (desmoplasia) was defined as the presence of a newly formed collagenous stroma surrounding the clusters of tumor cells and not present in the non-neoplastic thyroid parenchyma. The grade of desmoplasia was recorded as being negative $(-)$, low $(+)$, moderate $(++)$ or strong $(+++)$.

Statistical evaluation. The correlation between the histological grade of desmoplasia, the expression of the stromal markers (Tn-C, FAP $\alpha$ and $\alpha$-SMA) and the occurrence of lymph node metastases was evaluated in all cases of MTC. The KruskalWallis and the Mann-Whitney tests were used as appropriate. A two-tailed p-value of $<0.05$ was considered as significant.

In silico expression analysis. For in silico RNA-expression analysis, box and whisker plots were generated with the statistical computing package $\mathrm{R}$ based on normalized gene 
Table II. Clinicopathologic data of medullary thyroid carcinoma.

\begin{tabular}{|c|c|c|c|c|c|c|c|}
\hline Case no. & Age (years) & Gender & pTNM ${ }^{\mathrm{a}}$ & Diameter (mm) & Multifocal & Lymph node metastasis & C-cell hyperplasia \\
\hline 1 & 32 & f & pT1a & 8 & - & - & - \\
\hline 2 & 42 & $\mathrm{f}$ & pT1a & 4 & - & - & - \\
\hline 3 & 55 & $\mathrm{f}$ & pT1a & 3 & - & - & - \\
\hline 4 & 58 & $\mathrm{~m}$ & pT1a & 10 & - & - & + \\
\hline 5 & 66 & $\mathrm{f}$ & pT2a & 39 & - & - & - \\
\hline 6 & 55 & $\mathrm{~m}$ & pT2a & 11 & - & - & + \\
\hline 7 & 64 & $\mathrm{~m}$ & pT2a & 22 & - & - & - \\
\hline 8 & 52 & $\mathrm{f}$ & $\mathrm{pT} 2 \mathrm{a}$ & 28 & - & - & - \\
\hline 9 & 38 & $\mathrm{~m}$ & pT1b & 2 & + & - & + \\
\hline 10 & 54 & $\mathrm{f}$ & pT1a & 7 & - & - & + \\
\hline 11 & 38 & $\mathrm{~m}$ & $\mathrm{pT} 1 \mathrm{~b}$ & 7 & + & - & + \\
\hline 12 & 36 & $\mathrm{f}$ & pT1b & 6 & + & - & + \\
\hline 13 & 65 & $\mathrm{f}$ & pT1a & 8 & - & - & + \\
\hline 14 & 75 & $\mathrm{~m}$ & pT1a & 10 & - & - & + \\
\hline 15 & 55 & $\mathrm{f}$ & pT2b & 21 & + & - & + \\
\hline 16 & 69 & $\mathrm{f}$ & pT1b & 2 & + & - & + \\
\hline 17 & 70 & $\mathrm{~m}$ & pT1a & 8 & - & + & + \\
\hline 18 & 57 & $\mathrm{f}$ & pT1a & 9 & - & + & + \\
\hline 19 & 56 & f & $\mathrm{pT} 2 \mathrm{a}$ & 12 & - & + & - \\
\hline 20 & 24 & $\mathrm{f}$ & $\mathrm{pT} 2 \mathrm{~b}$ & 12 & + & + & - \\
\hline 21 & 71 & $\mathrm{~m}$ & $\mathrm{pT} 1 \mathrm{a}$ & 7 & - & + & + \\
\hline 22 & 64 & $\mathrm{f}$ & $\mathrm{pT} 2 \mathrm{a}$ & 13 & - & + & - \\
\hline 23 & 82 & f & pT2a & 15 & - & + & - \\
\hline 24 & 48 & f & pT4b & 30 & + & + & - \\
\hline 25 & 66 & $\mathrm{f}$ & pT4a & 18 & - & + & + \\
\hline 26 & 57 & $\mathrm{~m}$ & pT4a & 35 & - & + & - \\
\hline 27 & 76 & $\mathrm{~m}$ & pT2a & 40 & - & + & - \\
\hline 28 & 72 & $\mathrm{~m}$ & pT4a & 50 & - & + & - \\
\hline
\end{tabular}

f, female; m, male. ${ }^{\text {aUICC } 1997 .}$

expression data extracted from the BioExpress ${ }^{\mathrm{TM}}$ database (Gene Logic Inc., Gaithersburg, MD, USA) as reported (42). The bold center line in the box indicates the median, its left and right boundaries showing the first and third quartile of the data. Whiskers extend to 1.5 times the interquartile range; the position of extreme values, if above the upper whisker limits, are marked by a dot. The human sample collection has been described by the originator of the BioExpress ${ }^{\mathrm{TM}}$ database (42). The respective hybridizations were performed on Affymetrix HG-U133A/B oligonucleotide chips (Affymetrix Inc., Santa Clara, CA, USA); briefly, these chips are based on 25-mer oligonucleotides and allow the detection of more than 33,000 well-substantiated human genes, with probe sets of 11 oligonucleotides used per transcript.

Statistical analysis. Resultant chip analysis data were normalized with the statistical algorithm implemented in the Microarray Suite version 5.0 (Affymetrix Inc.). According to this algorithm, the raw expression intensity for a given chip experiment is multiplied by a global scaling factor to allow comparisons between chips. The scaling factor is calculated by removing the highest $2 \%$ and the lowest $2 \%$ of the values of the non-normalized expression values, and calculating the mean for the remaining values, as a trimmed mean. One hundred divided by the trimmed mean gives the scaling factor, where 100 is the standard value used by Gene Logic. Statistical significances of the differences between tumor and normal samples were verified by calculating t-test $p$-values. The Affymetrix identification code for FAP $\alpha$ is 209955_s_at, 201645_at for Tn-C, and 200974_at for $\alpha$-SMA.

\section{Results}

Patient data and tumor morphology. The study cases included 11 male and 17 female patients with a mean age of $57 \pm 14$ years, ranging from 24 to 82 years. The mean tumor diameter was $15.2 \pm 13 \mathrm{~mm}$, ranging from 2 to $50 \mathrm{~mm}$. All tumors showed typical MTC histology according to WHO criteria 
Table III. Characterization of the tumor stroma in MTC.

\begin{tabular}{|c|c|c|c|c|c|c|c|c|}
\hline \multirow[b]{3}{*}{ Case no. } & & & \multicolumn{6}{|c|}{ Immunohistochemistry } \\
\hline & \multicolumn{2}{|c|}{ Morphology } & \multicolumn{2}{|c|}{ Tenascin-C } & \multicolumn{2}{|c|}{$\mathrm{FAP} \alpha$} & \multicolumn{2}{|c|}{$\alpha-S M A$} \\
\hline & Desmoplasia & Degree & Intratumoral & Peritumoral & Intratumoral & Peritumoral & Intratumoral & Peritumoral \\
\hline 1 & No & - & - & + & - & + & + & ++ \\
\hline 2 & No & - & - & + & - & ++ & + & ++ \\
\hline 3 & No & - & + & + & - & + & ++ & ++ \\
\hline 4 & No & - & + & ++ & - & + & ++ & +++ \\
\hline 5 & No & - & + & ++ & + & ++ & + & +++ \\
\hline 6 & Yes & + & + & ++ & + & ++ & + & +++ \\
\hline 7 & Yes & + & + & ++ & - & + & ++ & ++ \\
\hline 8 & Yes & + & + & + & - & $*$ & + & + \\
\hline 9 & Yes & ++ & + & ++ & + & + & ++ & ++ \\
\hline 10 & Yes & ++ & + & + & + & ++ & ++ & ++ \\
\hline 11 & Yes & ++ & + & + & + & + & + & + \\
\hline 12 & Yes & ++ & ++ & ++ & ++ & ++ & ++ & ++ \\
\hline 13 & Yes & ++ & ++ & ++ & + & ++ & + & ++ \\
\hline 14 & Yes & ++ & ++ & + & + & ++ & ++ & ++ \\
\hline 15 & Yes & ++ & ++ & ++ & ++ & $*$ & ++ & ++ \\
\hline 16 & Yes & +++ & ++ & ++ & ++ & ++ & ++ & ++ \\
\hline 17 & Yes & ++ & + & ++ & ++ & +++ & ++ & +++ \\
\hline 18 & Yes & ++ & ++ & ++ & ++ & ++ & ++ & +++ \\
\hline 19 & Yes & ++ & ++ & ++ & + & ++ & ++ & +++ \\
\hline 20 & Yes & ++ & ++ & ++ & + & ++ & ++ & +++ \\
\hline 21 & Yes & +++ & ++ & ++ & + & ++ & ++ & +++ \\
\hline 22 & Yes & +++ & ++ & ++ & +++ & +++ & +++ & +++ \\
\hline 23 & Yes & +++ & ++ & ++ & ++ & ++ & ++ & ++ \\
\hline 24 & Yes & +++ & ++ & ++ & + & ++ & + & ++ \\
\hline 25 & Yes & +++ & +++ & +++ & ++ & ++ & ++ & +++ \\
\hline 26 & Yes & +++ & +++ & +++ & ++ & +++ & ++ & ++ \\
\hline 27 & Yes & +++ & +++ & +++ & ++ & +++ & ++ & +++ \\
\hline 28 & Yes & +++ & +++ & +++ & +++ & +++ & +++ & +++ \\
\hline
\end{tabular}

-, negative; +, low; ++, moderate; +++, strong; ${ }^{*}$, not available.

and calcitonin expression by immunohistochemistry. Fourteen cases were classified as pT1, therefore considered microcarcinomas, ten cases were pT2 and the remaining four cases were diagnosed as pT4 according to the UICC 1997 guidelines. Multifocality was seen in 7 patients, all these were familial. Concomitant $\mathrm{C}$-cell hyperplasia $(\mathrm{CCH})$ was found in 14 cases ( 8 sporadic, 6 hereditary cases). Twelve MTC had metastasized to the regional lymph nodes (Table II). Latent papillary thyroid microcarcinoma was found in the adjacent thyroid gland in three of the 28 patients with MTC. Five of the 28 patients showed evidence of autoimmune thyroiditis, and thirteen patients displayed nodular thyroid disease.

Histopathology. Desmoplasia was found in 23 of 28 (82\%) tumors studied. The grade of desmoplasia was low in 3 $(11 \%)$, and moderate to strong in $20(71 \%)$ of the cases. Five tumors (18\%) had no desmoplastic stroma reaction
(Table III). Examples of MTC with prominent, moderate and no desmoplasia are shown in Fig. 1a, $\mathrm{d}$ and $\mathrm{g}$.

Expression patterns of Tn-C, FAP $\alpha$ and $\alpha$-SMA in the tumor stroma. In the normal thyroid gland no Tn-C and FAP $\alpha$ expression was observed within the stroma or in the follicular epithelium and the expression of $\alpha$-SMA was confined to the smooth muscle cells/pericytes in the vasculature. In contrast, all three markers were strongly upregulated in the tumor stromal fibroblasts of MTC (Table III).

Tn-C expression was seen in the majority of cases both in the intratumoral and peritumoral stroma compartment. The expression within the intratumoral compartment was moderate to strong in sixteen cases (Fig. 1b), ten tumors showed weak expression, and the two remaining were negative (Fig. 1h). $\mathrm{Tn}-\mathrm{C}$ expression in the peritumoral compartment appeared to be more homogeneous with moderate to strong expression seen 

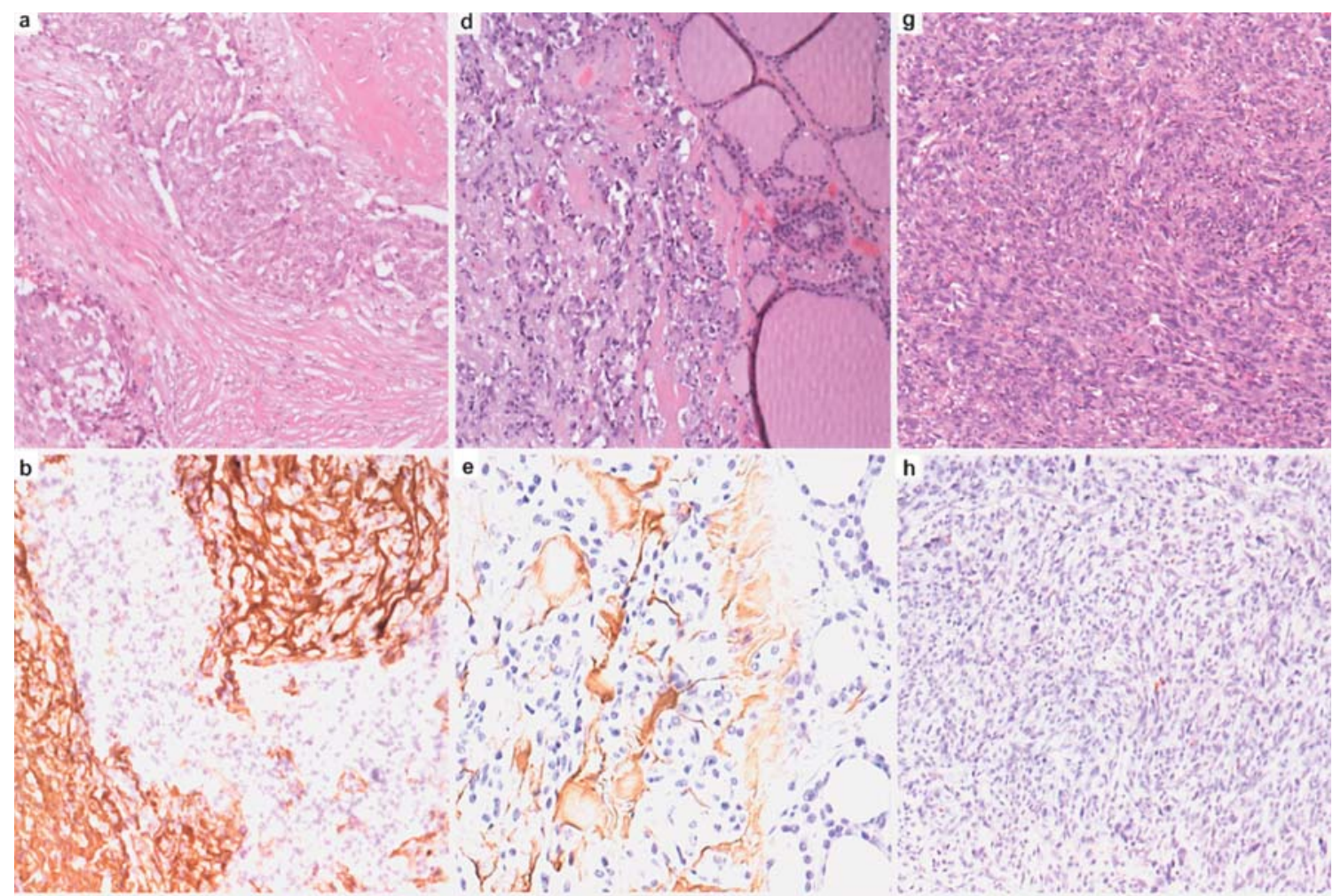

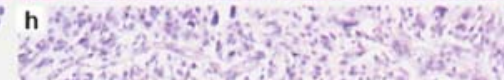
C.t.

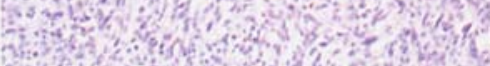

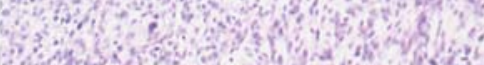
H. W $35=$

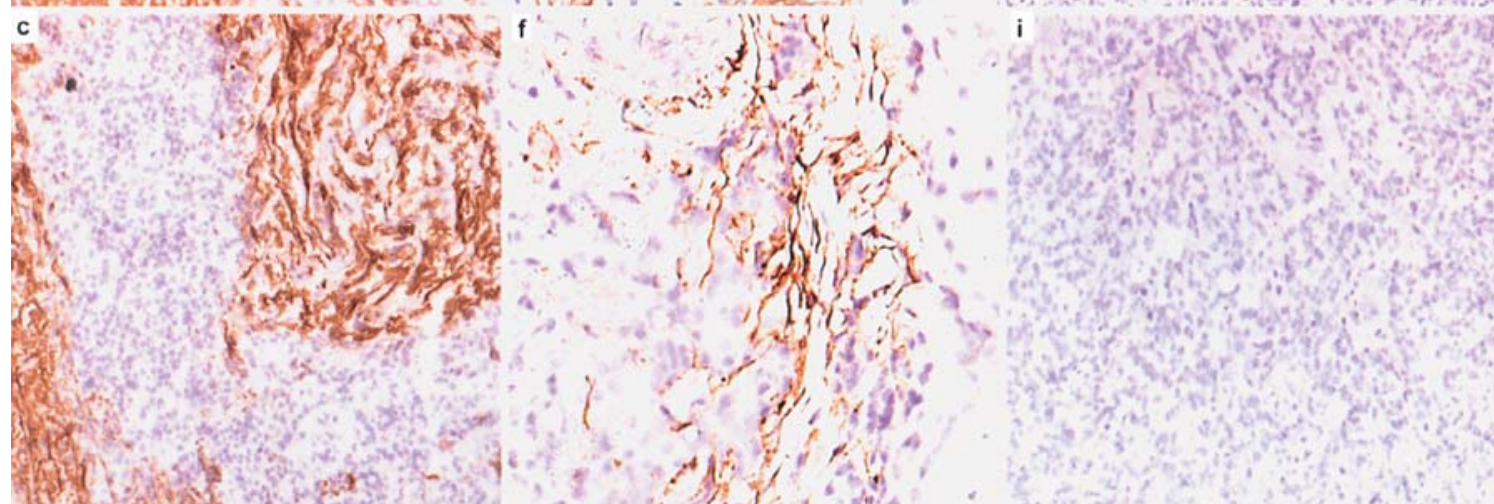

Figure 1. Desmoplastic stroma reaction in medullary thyroid carcinoma (MTC). a, MTC with prominent desmoplastic tumor stroma (case 28). Dense bands of intratumoral collagenous stroma separating the clusters of tumor cells (H\&E). b, Tn-C expression in adjacent sections from the same tumor. c, FAP $\alpha$ expression in tumor stromal fibroblasts. d, peritumoral stroma compartment of an MTC (case 13) with moderate desmoplastic reaction (H\&E). e, Tn-C expression in the peritumoral stroma. f, FAP $\alpha$ expression by peritumoral activated fibroblasts from the corresponding tumor. g, MTC without desmoplastic stroma reaction (case 1) (H\&E). Adjacent sections stained with Tn-C (h) and FAP $\alpha$ (i) are negative for both stromal markers. Hematoxylin and eosin staining (a, $\mathrm{d}, \mathrm{g}$ ). Tn-C expression is shown in $\mathrm{b}, \mathrm{e}$ and $\mathrm{h}$, and FAP $\alpha$ expression in $\mathrm{c}, \mathrm{f}$ and $\mathrm{i}$, by the $\mathrm{ABC}$ immunoperoxidase method with hematoxylin counterstaining. Original magnification $\mathrm{x} 100$.

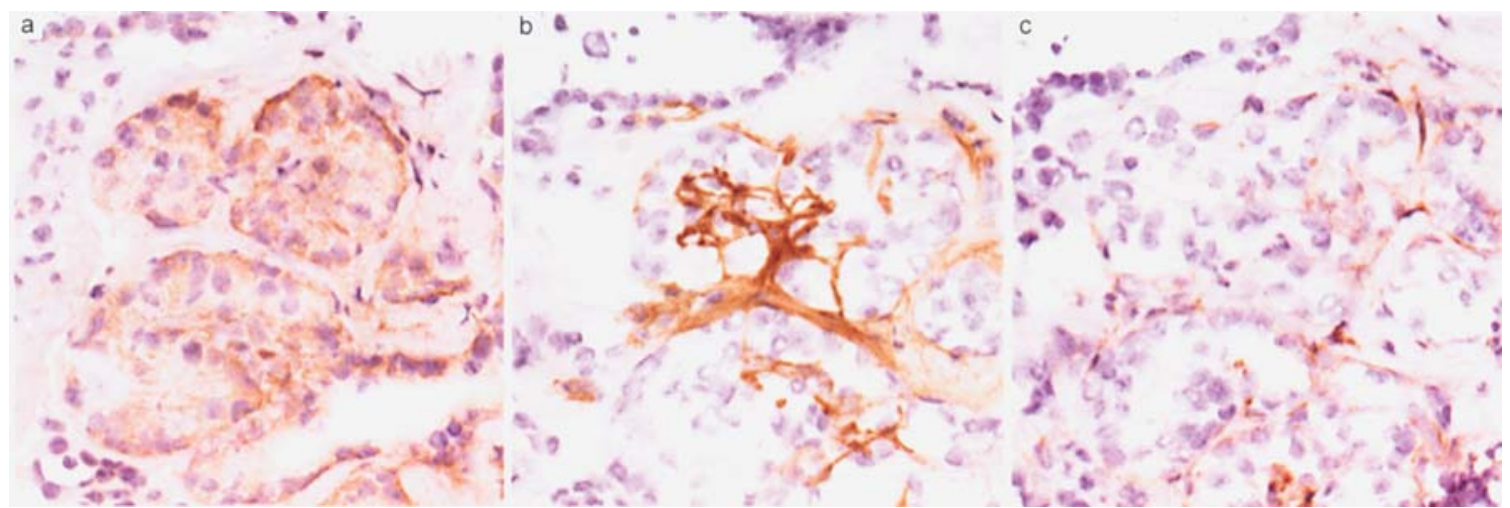

Figure 2. C-cell hyperplasia (CCH) in a multifocal MTC. a, calcitonin-positive cells in areas of CCH adjacent to an MTC. b, Tn-C immunoreactivity was observed in the fibroblast and extracellular matrix surrounding the C-cell clusters. c, FAP $\alpha$ immunoreactivity in scattered stromal fibroblasts in close proximity to the C-cells. Original magnification x 200 . 


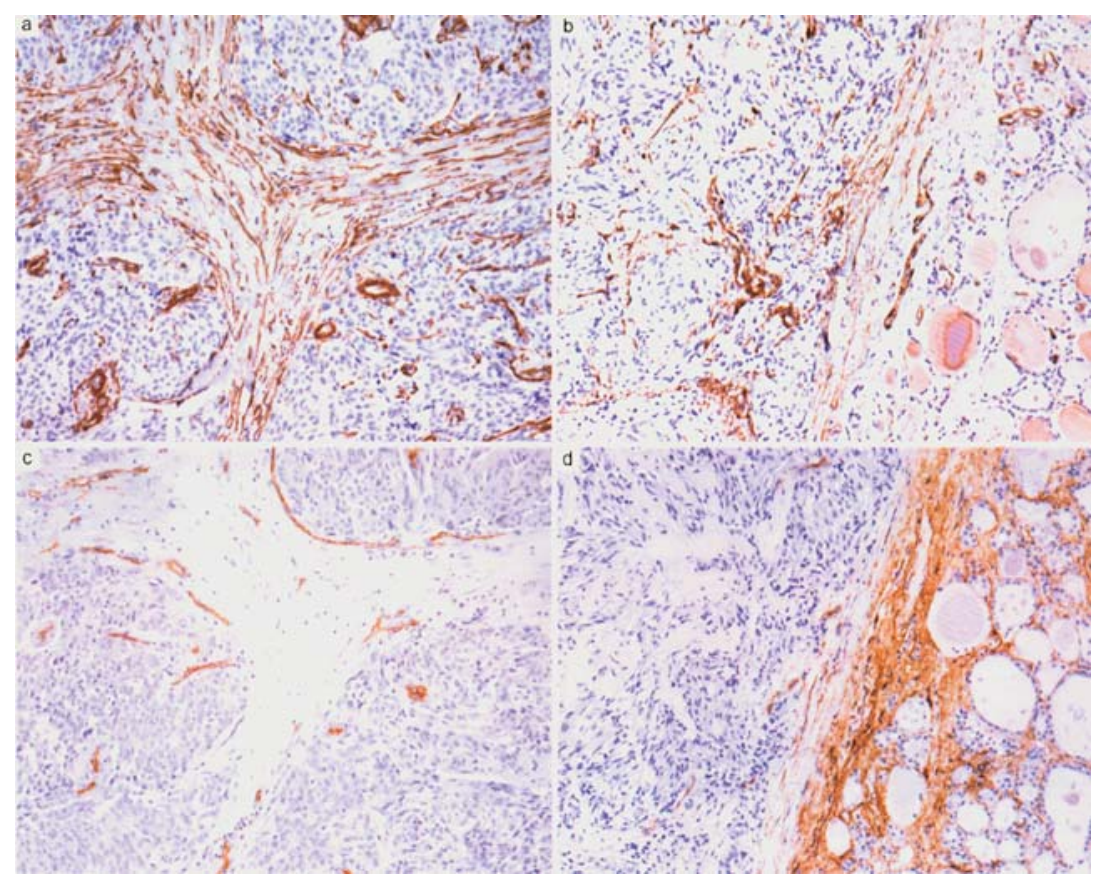

Figure 3. Expression of $\alpha$-SMA and CD34 in MTC. a, expression of $\alpha$-SMA in activated stromal fibroblasts surrounding the nodules of tumor cells and in vascular smooth muscle cells of the tumor vasculature (case 28). b, in the non-involved thyroid gland expression of $\alpha$-SMA was limited to the vascular smooth muscle cells, whereas in the tumor nodules expression occurred in reactive fibroblasts/myofibroblasts in the peritumoral and intratumoral compartment as well as in the tumor vessels (case 7). c, CD34 expression by vascular endothelial cells within the tumor nodules (case 28). d, expression of CD34 in the fibroblast of the adjacent non-involved thyroid gland and no expression by the tumor activated fibroblasts (case 7). Original magnification x40.
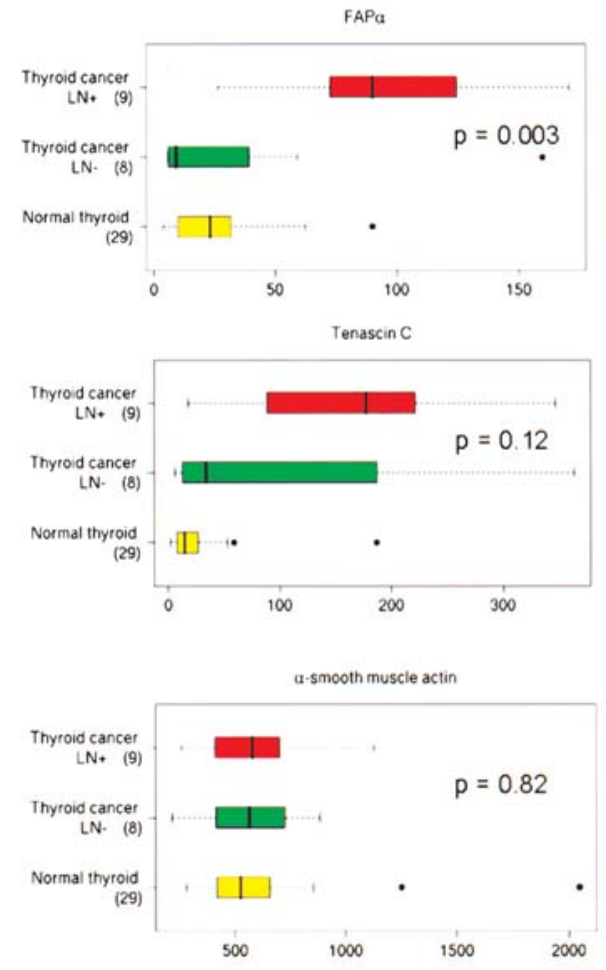

Figure 4. In silico analysis of stromal markers in metastatic and non-metastatic papillary thyroid cancers. For expression analysis, whisker-box plots were generated using the statistical computing package $\mathrm{R}$, based on normalized gene expression data from BioExpress $\mathrm{R}$ database (Gene Logic). Box plots represent the range from the first quartile $(25 \%)$ to the third quartile $(75 \%)$ of the distribution. The bold lines in each box indicate median values $(50 \%$ quartile); the whiskers extend to 1.5 times the interquartile range. Expression patterns for FAP $\alpha$, Tn-C and $\alpha$-SMA are shown for metastatic (red boxes) and non-metastatic papillary cancers (green boxes), and normal thyroid tissue (yellow boxes). The p-values relate to the expression differences of metastatic vs. non-metastatic carcinomas calculated by Student's t-tests. in twenty-one cases (Fig. 1e) and low in the remaining seven cases. A significant correlation between the intratumoral Tn-C expression and the grade of desmoplasia was demonstrated $(\mathrm{p}<0.001)$. Tn-C expression appeared to be localized to the tumor stromal fibroblasts (Fig. 1b), in other instances it appeared as a secreted protein filling the intercellular spaces (Fig. 1e), and in the vascular smooth muscle cells. In addition, intracytoplasmatic staining of tumor cells was observed in seven cases (data not shown). Induction of $\mathrm{Tn}-\mathrm{C}$ was observed in areas of $\mathrm{CCH}$ (Fig. 2b).

FAP $\alpha$ was seen in the activated tumor stromal fibroblasts of the peritumoral and intratumoral compartment in most cases. Prominent intratumoral immunoreactivity (Fig. 1c) was seen in eleven cases, all of which were classified histologically as having prominent desmoplasia. Eleven cases showed weak FAP $\alpha$ expression and six cases were negative (Fig. 1i). In the peritumoral stromal compartment, the expression of FAP $\alpha$ was moderate to strong in twenty cases (Fig. 1f), and weak in six cases. In the remaining two cases no peritumoral frozen tissue was available for analysis. The correlation between FAP $\alpha$ expression in the intratumoral stromal compartment and the grade of desmoplasia determined histologically was highly significant $(\mathrm{p}=0.001)$.

FAP $\alpha$ expression was observed in areas of concomitant $\mathrm{CCH}$ in fibroblasts surrounding the clusters of calcitoninpositive C-cells (Fig. 2c).

$\alpha$-SMA expression was seen in all cases of MTC (Fig. 3a and $b$ ). The intratumoral expression of $\alpha$-SMA was moderate to strong in twenty cases (Fig. 3b) and low in the remaining eight cases which displayed only few intratumoral $\alpha$-SMApositive myofibroblasts. Twenty-six cases (93\%) showed moderate to strong immunoreactivity in the peritumoral stroma 
(Fig. 3a) with low expression in the remaining two cases. The intratumoral expression of $\alpha$-SMA did not correlate significantly with the extent of histological desmoplasia $(\mathrm{p}>0.05)$.

In the thyroid tissue surrounding the MTC, an expression of FAP $\alpha$ and TN-C was observed in fibroblasts surrounding the clusters of lymphocyte infiltration whenever a thyroiditis was present.

Expression patterns of endoglyx-1, PECAM (CD31), and CD34. The vascular markers endoglyx-1, PECAM (CD31), and CD34 were used to analyze the extent of vascularization in MTC. All three markers were expressed by the endothelial cells in the normal thyroid gland and by the tumor blood vessels (Fig. 3c and d). In addition, CD34 expression was seen in the normal fibroblasts of the non-involved thyroid gland adjacent to the tumor nodules but not in the activated tumor stromal fibroblasts (Fig. 3d). A mean MVD of 56.71 was found, with a range of 23 to 108 blood vessels per $0.25 \mathrm{~mm}^{2}$ of tumor area. No correlation was found between MVD, the grade of desmoplasia, the upregulation of the stromal markers or the presence of lymph node metastasis.

Correlation between tumor size, desmoplasia, expression of stromal markers and lymph node metastasis. A significant correlation was observed between the grade of desmoplasia and the presence of lymph node metastasis. The twelve cases with lymph node metastasis showed prominent desmoplasia at the histological level $(\mathrm{p}=0.002)$. In contrast, no lymph node metastasis was observed in cases with low or no desmoplasia. Similarly, the intratumoral expression of $\mathrm{Tn}-\mathrm{C}$ and FAP $\alpha$ showed significant correlation with nodal involvement ( $p=0.002$ for Tn-C; $\mathrm{p}=0.005$ for $\mathrm{FAP} \alpha$ ).

Neither the presence of lymph node metastasis, the extent or presence of desmoplasia nor $\mathrm{Tn}-\mathrm{C}$ and $\mathrm{FAP} \alpha$ expression were correlated to tumor diameter.

In silico analysis of thyroid cancers. Microarray studies have allowed the analysis of thousands of genes simultaneously and the relative ease and speed of performing eNortherns in the BioExpress database has provided a comprehensive view of the genetic changes in normal and disease tissues, thus representing a high-throughput approach for identifying putative regulators of cancer stroma induction that may show distinct patterns of co-regulation in normal and tumor tissues.

The expression levels of FAP $\alpha, \mathrm{Tn}-\mathrm{C}$ and $\alpha$-SMA in thyroid cancers were analyzed by querying the Gene Logic Bioexpress database (see Materials and methods). In this database, we obtained the respective gene-expression profiles for a set of 48 thyroid cancers including three anaplastic carcinomas, 6 follicular carcinomas, 2 medullary carcinomas, and 37 papillary carcinomas. The control set of normal thyroid consisted of histologically normal thyroid gland obtained from patients with thyroid cancer $(n=29)$. Sample diagnoses and clinical data were taken at face value from the database.

Compared to normal thyroid tissue we found FAP $\alpha$ and Tn-C upregulated in the 48 cancers. In 17 papillary carcinomas data on the lymph node status were available. We observed a prominent upregulation of FAP $\alpha$ transcripts (4.2-fold change) in metastatic thyroid cancers $(n=9)$ compared to the lymph node $(\mathrm{LN})$ negative cancers $(\mathrm{n}=8)(\mathrm{p}=0.003)$. In addition, we found a 2.8-fold upregulation of $\mathrm{Tn}-\mathrm{C}$ transcripts in the metastatic thyroid cancers when compared to the non-metastatic lesions $(\mathrm{p}=0.12)$. In contrast, the expression of $\alpha$-SMA appeared to be only slightly increased in the metastatic cancers compared to the non-metastatic tumors $(\mathrm{p}=0.82)$ probably reflecting the fact that $\alpha$-SMA is expressed in cell types other than the activated tumor stromal fibroblasts, such as vascular smooth muscle cells in the normal and tumor vasculature (Fig. 4).

\section{Discussion}

We have shown previously that MTC with a desmoplastic stroma reaction have a higher incidence of lymph node metastasis $(5,6)$. In this study, we have examined the expression pattern of three molecular markers of activated stromal fibroblasts, namely, FAP $\alpha$, Tn-C and $\alpha$-SMA as well as the endothelial markers endoglyx-1, CD34 and CD31 in a series of 28 metastatic and non-metastatic MTC. We demonstrate that all three fibroblast activation markers (FAP $\alpha, \mathrm{Tn}-\mathrm{C}$ and $\alpha$-SMA) are consistently expressed in the peritumoral and intratumoral stromal compartment of MTC. This stromal cell phenotype differs from the stromal cells of the normal thyroid gland, which is composed of CD $34^{+}, \mathrm{FAP} \alpha^{-}$, Tn- $\mathrm{C}^{-}$and $\alpha-\mathrm{SMA}$ fibroblasts. A significant correlation was observed in our study between the degree of desmoplasia determined histologically and the expression of FAP $\alpha$ and Tn-C. Moreover, the extent of desmoplasia as well as the expression of FAP $\alpha$ and Tn-C correlated significantly with the presence of lymph node metastases, a novel finding derived from this analysis. Expression of FAP $\alpha$ in activated tumor stromal fibroblasts has been shown to occur in a large proportion of human epithelial cancers and in melanocytic skin tumors $(16,23,24)$. In these tissues, FAP $\alpha$ functions as an active serine protease capable of degrading type I collagen, and dipeptidyl-peptidase activity, thus suggesting that FAP $\alpha$ may be involved in direct remodeling of the extracellular matrix during cancer invasion or modification of regulatory mediators $(17,24)$. Our results on Tn-C expression in MTC are in agreement with a recent study showing $\mathrm{Tn}-\mathrm{C}$ expression at the protein and mRNA level in thyroid cancer (43). Upregulation of $\mathrm{Tn}-\mathrm{C}$ has been demonstrated in many human cancers $(32,44)$, and this increased expression correlated with poor prognosis and increased invasiveness in some studies $(33,34)$. Interestingly, our results indicate that the stromal activation is an early event in the process of tumorigenesis in MTC. FAP $\alpha$ and Tn-C expression were seen in the stroma of microcarcinomas and in areas of concomitant $\mathrm{CCH}$. Similar observations have been made for $\mathrm{Tn}-\mathrm{C}$ expression in pre-cancerous lesions of other organs, such as the prostate and cervix $(45,46)$. In addition, FAP $\alpha$ and Tn-C expression were observed in areas of autoimmune thyroiditis accompanying some of the MTC cases consistent with their link to inflammatory tissue remodeling. No correlation was found in our cases between the microvessel density or hot spots of neoangiogenesis and the degree of desmoplasia or incidence of lymph node metastases.

We have extended the molecular characterization of the desmoplastic tumor stroma to other types of thyroid cancer, focusing on the expression of FAP $\alpha$, Tn-C and $\alpha$-SMA using 
the BioExpress database for a bioinformatics search of specific mRNA transcripts. Unfortunately this database harbours only two cases of medullary thyroid carcinoma. However the key finding of this analysis was the significant correlation between FAP $\alpha$ RNA expression and incidence of LN metastases in a series of 17 thyroid cancers of papillary type.

In summary, our findings show that FAP $\alpha$ and Tn-C constitute markers of tumor stroma activation in MTC and suggest that the link between specific molecular markers of tumor stromal reaction and loco-regional metastasis extends from medullary to other thyroid cancer types. Functional studies are required to determine a potential role of these proteins in the process of LN metastasis. Conceivably, the molecular characterization of the stromal reaction in MTC may provide future guidance for the surgical strategy of cervical lymph node resection.

\section{References}

1. Rosai J, Carangiu M and DeLellis R: Atlas of Tumor Pathology: Tumors of the Thyroid Gland. Rosai J and Sobin L (eds). Armed Forces Institute of Pathology, Washington DC, 1992.

2. Moley JF and DeBenedetti MK: Patterns of nodal metastases in palpable medullary thyroid carcinoma: recommendations for extent of node dissection. Ann Surg 229: 880-888, 1999.

3. Beressi N, Campos JM, Beressi JP, Franc B, Niccoli-Sire P, Conte-Devolx B, Murat A, Caron P, Baldet L, Kraimps JL, Cohen R, Bigorgne JC, Chabre O, Lecomte P and Modigliani E: Sporadic medullary microcarcinoma of the thyroid: a retrospective analysis of eighty cases. Thyroid 8: 1039-1044, 1998.

4. Scollo C, Baudin E, Travagli JP, Caillou B, Bellon N, Leboulleux $\mathrm{S}$ and Schlumberger M: Rationale for central and bilateral lymph node dissection in sporadic and hereditary medullary thyroid cancer. J Clin Endocrinol Metab 88: 2070-2075, 2003.

5. Kaserer K, Scheuba C, Neuhold N, Weinhausel A, Haas OA, Vierhapper $\mathrm{H}$ and Niederle B: Sporadic versus familial medullary thyroid microcarcinoma: a histopathologic study of 50 consecutive patients. Am J Surg Pathol 25: 1245-1251, 2001.

6. Scheuba C, Kaserer K, Kaczirek K, Asari R and Niederle B: Desmoplastic stromal reaction in medullary thyroid cancer - an intraoperative 'marker' for lymph node metastases. World J Surg 30: 853-859, 2006.

7. Dvorak HF: Tumors: wounds that do not heal. Similarities between tumor stroma generation and wound healing. N Engl J Med 315: 1650-1659, 1986.

8. Liotta LA and Kohn EC: The microenvironment of the tumourhost interface. Nature 411: 375-379, 2001.

9. Bissell MJ and Radisky D: Putting tumours in context. Nat Rev Cancer 1: 46-54, 2001.

10. De Wever O and Mareel M: Role of tissue stroma in cancer cell invasion. J Pathol 200: 429-447, 2003.

11. Kunz-Schughart LA and Knuechel R: Tumor-associated fibroblasts (part I): Active stromal participants in tumor development and progression? Histol Histopathol 17: 599-621, 2002.

12. Kunz-Schughart LA and Knuechel R: Tumor-associated fibroblasts (part II): Functional impact on tumor tissue. Histol Histopathol 17: 623-637, 2002.

13. Bhowmick NA, Neilson EG and Moses HL: Stromal fibroblasts in cancer initiation and progression. Nature 432: 332-337, 2004.

14. Orimo A, Gupta PB, Sgroi DC, Arenzana-Seisdedos F, Delaunay T, Naeem R, Carey VJ, Richardson AL and Weinberg RA: Stromal fibroblasts present in invasive human breast carcinomas promote tumor growth and angiogenesis through elevated SDF-1/CXCL12 secretion. Cell 121: 335-348, 2005.

15. Desmouliere A, Guyot C and Gabbiani G: The stroma reaction myofibroblast: a key player in the control of tumor cell behavior. Int J Dev Biol 48: 509-517, 2004.

16. Garin-Chesa P, Old LJ and Rettig WJ: Cell surface glycoprotein of reactive stromal fibroblasts as a potential antibody target in human epithelial cancers. Proc Natl Acad Sci USA 87: 7235-7239, 1990.
17. Park JE, Lenter MC, Zimmermann RN, Garin-Chesa P, Old LJ and Rettig WJ: Fibroblast activation protein, a dual specificity serine protease expressed in reactive human tumor stromal fibroblasts. J Biol Chem 274: 36505-36512, 1999.

18. Chiquet-Ehrismann R, Mackie EJ, Pearson CA and Sakakura T: Tenascin: an extracellular matrix protein involved in tissue interactions during fetal development and oncogenesis. Cell 47: 131-139, 1986.

19. Jones PL: Extracellular matrix and tenascin-C in pathogenesis of breast cancer. Lancet 357: 1992-1994, 2001.

20. Sappino AP, Skalli O, Jackson B, Schurch W and Gabbiani G: Smooth-muscle differentiation in stromal cells of malignant and non-malignant breast tissues. Int J Cancer 41: 707-712, 1988.

21. Serini G and Gabbiani G: Mechanisms of myofibroblast activity and phenotypic modulation. Exp Cell Res 250: 273-283, 1999.

22. Rettig WJ, Garin-Chesa P, Healey JH, Su SL, Ozer HL, Schwab M, Albino AP and Old LJ: Regulation and heteromeric structure of the fibroblast activation protein in normal and transformed cells of mesenchymal and neuroectodermal origin. Cancer Res 53: 3327-3335, 1993.

23. Scanlan MJ, Raj BK, Calvo B, Garin-Chesa P, Sanz-Moncasi MP, Healey JH, Old LJ and Rettig WJ: Molecular cloning of fibroblast activation protein alpha, a member of the serine protease family selectively expressed in stromal fibroblasts of epithelial cancers. Proc Natl Acad Sci USA 91: 5657-5661, 1994.

24. Huber MA, Kraut N, Park JE, Schubert RD, Rettig WJ, Peter RU and Garin-Chesa P: Fibroblast activation protein: differential expression and serine protease activity in reactive stromal fibroblasts of melanocytic skin tumors. J Invest Dermatol 120: 182-188, 2003.

25. Dolznig H, Schweifer N, Puri C, Kraut N, Rettig WJ, Kerjaschki D and Garin-Chesa P: Characterization of cancer stroma markers: in silico analysis of an mRNA expression database for fibroblast activation protein and endosialin. Cancer Immun 5: 10, 2005.

26. Huber MA, Kraut N, Schweifer N, Dolznig H, Peter RU, Schubert RD, Scharffetter-Kochanek K, Pehamberger H and Garin-Chesa P: Expression of stromal cell markers in distinct compartments of human skin cancers. J Cutan Pathol 33: 145-155, 2006.

27. Hauptmann S, Budianto D, Denkert C, Kobel M, Borsi L and Siri A: Adhesion and migration of HRT-18 colorectal carcinoma cells on extracellular matrix components typical for the desmoplastic stroma of colorectal adenocarcinomas. Oncology 65: 174-181, 2003.

28. Chiquet-Ehrismann R and Tucker RP: Connective tissues: signalling by tenascins. Int J Biochem Cell Biol 36: 1085-1089, 2004.

29. Sethi T, Rintoul RC, Moore SM, MacKinnon AC, Salter D, Choo C, Chilvers ER, Dransfield I, Donnelly SC, Strieter R and Haslett C: Extracellular matrix proteins protect small cell lung cancer cells against apoptosis: a mechanism for small cell lung cancer growth and drug resistance in vivo. Nat Med 5: 662-668, 1999.

30. Maschler S, Grunert S, Danielopol A, Beug H and Wirl G: Enhanced tenascin- $\mathrm{C}$ expression and matrix deposition during Ras/TGF-beta-induced progression of mammary tumor cells. Oncogene 23: 3622-3633, 2004.

31. Garin-Chesa P, Melamed MR and Rettig WJ: Immunohistochemical analysis of human neuronectin expression in normal, reactive, and neoplastic tissues. J Histochem Cytochem 37: 1767-1776, 1989.

32. Howeedy AA, Virtanen I, Laitinen L, Gould NS, Koukoulis GK and Gould VE: Differential distribution of tenascin in the normal, hyperplastic, and neoplastic breast. Lab Invest 63: 798-806, 1990.

33. Ishihara A, Yoshida $\mathrm{T}$, Tamaki $\mathrm{H}$ and Sakakura T: Tenascin expression in cancer cells and stroma of human breast cancer and its prognostic significance. Clin Cancer Res 1: 1035-1041, 1995.

34. Hauptmann S, Zardi L, Siri A, Carnemolla B, Borsi L, Castellucci M, Klosterhalfen B, Hartung P, Weis J, Stocker G, et al: Extracellular matrix proteins in colorectal carcinomas. Expression of tenascin and fibronectin isoforms. Lab Invest 73: 172-182, 1995.

35. Rettig WJ, Erickson HP, Albino AP and Garin-Chesa P: Induction of human tenascin (neuronectin) by growth factors and cytokines: cell type-specific signals and signalling pathways. J Cell Sci 107: 487-497, 1994.

36. Folkman J: Tumor angiogenesis: therapeutic implications. N Engl J Med 285: 1182-1186, 1971. 
37. Carmeliet P: Angiogenesis in health and disease. Nat Med 9: 653-660, 2003.

38. Weidner N, Semple JP, Welch WR and Folkman J: Tumor angiogenesis and metastasis - correlation in invasive breast carcinoma. N Engl J Med 324: 1-8, 1991.

39. Macchiarini P, Fontanini G, Hardin MJ, Squartini F and Angeletti CA: Relation of neovascularisation to metastasis of non-small-cell lung cancer. Lancet 340: 145-146, 1992.

40. Weidner N: Current pathologic methods for measuring intratumoral microvessel density within breast carcinoma and other solid tumors. Breast Cancer Res Treat 36: 169-180, 1995.

41. Birner P, Piribauer M, Fischer I, Gatterbauer B, Marosi C, Ambros PF, Ambros IM, Bredel M, Oberhuber G, Rossler K, Budka H, Harris AL and Hainfellner JA: Vascular patterns in glioblastoma influence clinical outcome and associate with variable expression of angiogenic proteins: evidence for distinct angiogenic subtypes. Brain Pathol 13: 133-143, 2003.
42. Shen-Ong GL, Feng Y and Troyer DA: Expression profiling identifies a novel alpha-methylacyl-CoA racemase exon with fumarate hydratase homology. Cancer Res 63: 3296-3301, 2003.

43. Tseleni-Balafouta S, Gakiopoulou H, Fanourakis G, Voutsinas G, Balafoutas D and Patsouris E: Tenascin-C protein expression and mRNA splice variants in thyroid carcinoma. Exp Mol Pathol 80: 177-182, 2006.

44. Brunner A, Mayerl C, Tzankov A, Verdorfer I, Tschorner I, Rogatsch $\mathrm{H}$ and Mikuz G: Prognostic significance of tenascin-C expression in superficial and invasive bladder cancer. J Clin Pathol 57: 927-931, 2004

45. Tuxhorn JA, Ayala GE, Smith MJ, Smith VC, Dang TD and Rowley DR: Reactive stroma in human prostate cancer: induction of myofibroblast phenotype and extracellular matrix remodeling. Clin Cancer Res 8: 2912-2923, 2002.

46. Iskaros BF and Koss LG: Tenascin expression in intraepithelial neoplasia and invasive carcinoma of the uterine cervix. Arch Pathol Lab Med 124: 1282-1286, 2000. 